\title{
Estudos Científicos em Administração: A Influência dos dados coletados para melhoria organizacional
}

\author{
Bianca Alves Oliveiral Alyne Leite de Oliveira ${ }^{2}$
}

Resumo: A pesquisa tem como principal objetivo verificar a incidência de aplicação dos resultados coletados nos estudos de caso realizados no ano de 2017, a partir da análise dos TCC's deste mesmo ano, do curso de administração de uma IES privada, e que apresentaram em seus diagnósticos a necessidade de implementação de ferramentas de melhoria para empresas estudadas em Juazeiro do Norte-Ce. Após a seleção dos trabalhos, foram realizadas entrevistas com os gestores e análise dos dados coletados por meio da análise de conteúdo (AC). O estudo realizado mostrou-se favorável ao desempenho das pesquisas na área de gestão, visto que os participantes se apresentaram disponíveis à realização da investigação, destacando a aplicabilidade das ferramentas e procedimentos sugeridos a partir das análises, bem como mensurando resultados satisfatórios após a aplicação dos mesmos.

Palavras Chave: Pesquisa Científica. Aplicação de estudos. Desempenho organizacional.

\section{Scientific Studies in Administration: The influence of data collected for organizational improvement}

\begin{abstract}
The research has as main objective to verify the incidence of application of the results collected in the case studies accomplished in the year of 2017, starting from the analysis of TCC's of this same year, of the course of administration of a private IES, and that presented in their diagnoses the need of implementation of improvement tools for companies studied in Juazeiro of the North-Ce. After the selection of the works, interviews were accomplished with the managers and analysis of the data collected through the content (AC) analysis. The accomplished study was shown favorable to the acting of the researches in the administration area, because the participants came available to the accomplishment of the investigation, detaching the applicability of the tools and procedures suggested starting from the analyses, as well as measuring satisfactory results starting from the application of the same ones.
\end{abstract}

Keywords: Scientific Research. Application of studies. Organizational performance.

\section{Introdução}

Ao se observar o que menciona Alves (1981) quando destaca que "quando os cientistas compreenderem que eles pertencem ao mesmo clube que os caçadores, pescadores e detetives, descobriram que o seu trabalho é muito mais excitante do que pode parecer", se percebe uma analogia

\footnotetext{
${ }^{1}$ Graduanda do curso de administração do Centro Universitário Doutor Leão Sampaio - UNILEÃO. biancaalvesoliveiradm@gmail.com;

${ }^{2}$ Professor orientador do Centro Universitário Doutor Leão Sampaio/UNILEÃO, especialista em logística empresarial, mestranda em Direito da Empresa e dos Negócios. alyneoliveira@ leaosampaio.edu.br. 
aos papéis dos mesmos no destaque à busca incessante por descobertas que venham à saciar às necessidades preponderantes em cada área. Porém, nem sempre esse aspecto é percebido por todos com o encantamento sugerido pelo autor, muitas vezes discutindo inclusive a aplicabilidade dessas descobertas, fundamentalmente nas áreas de gestão.

A prática da pesquisa científica vem se disseminando de forma mais rápida devido à inserção de um maior número de estudantes no ensino superior nos últimos anos. Este fato difunde oportunidades para os mesmos aprimorarem os seus conhecimentos, adentrando-se a um conhecimento mais amplo, e criando projetos que podem influenciar no andamento das instituições.

É a partir da pesquisa que o acadêmico pode, não apenas compreender como ocorrem os processos nas organizações, mas enveredar pelo universo da investigação e ocorrência dos fatos, os gargalos a serem resolvidos, bem como desenvolver o senso crítico acerca das atividades existentes nesses ambientes, consolidando o conhecimento a partir do desenvolvimento de trabalho de conclusão de curso ou mesmo de estudos desenvolvidos no decorrer da vida acadêmica. Porém o que se percebe muitas vezes, é que esse conhecimento se limita a ficar no papel, quando poderia contribuir com a modificação de sociedade avaliada.

Frente à esses aspectos, surgiu o interesse em entender melhor: qual o fim dado aos levantamentos realizados a partir do desenvolvimento dos estudos citados anteriormente? Como são consolidadas as práticas relacionadas ao cenário da pesquisa no âmbito organizacional? Será que as organizações põem em prática o que foi estudado e planejado? De que forma a organização consegue eficácia a partir dos dados coletados? Esses métodos trabalhados conduzem a resultados satisfatórios?

Desse modo, o estudo aqui apresentado tem por objetivo geral verificar a incidência de aplicação dos resultados coletados nos estudos de caso realizados no ano de 2017, a partir da análise dos Trabalhos de Conclusão de Curso (TCC's) deste mesmo ano, do curso de administração de uma instituição de ensino superior (IES) privada, e que apresentaram em seus diagnósticos a necessidade de implementação de ferramentas de melhoria para empresas estudadas em Juazeiro do Norte-Ce. Como objetivos específicos, tratou-se de discutir sobre a influência da pesquisa científica no âmbito organizacional, verificar se foram aplicadas as propostas apontadas nas pesquisas conforme o que foi proposto para organização, e se as aplicações dos estudos ficaram explícitos, averiguando também os fatores de melhoria trazidos por essa coleta de dados.

Os benefícios desse estudo perpassam as discussões acadêmicas e publicações de trabalho, adentrando reflexões para os participantes da pesquisa que poderão não apenas 
compreender as limitações inerentes às mudanças operacionais propostas por estudos anteriores, mas principalmente entender a importância da aplicação das ferramentas propostas a partir do diagnóstico e usufruto das melhorias implantadas. Ou seja, além da realização de um diagnóstico da sua realidade, a possibilidade de aplicação de ferramentas viáveis à sua melhoria organizacional.

\section{Pesquisa Científica}

As pessoas vivem em um universo em que podem frequentemente ser alvos ou frutos de investigações, seja pelas práticas empíricas ou de cunho científico. Ramos (2009) associa as práticas cotidianas à ciência, onde ela será a bússola que dá às pessoas a certeza de onde partir e para onde chegar. A ciência é a base do conhecimento e também dos questionamentos que direcionam as pessoas a críticas e a investigações.

A busca se efetiva a partir da necessidade de explicações para a realidade, que surge com a formulação de problemas, ou seja, é o que é preciso ser pesquisado, que na percepção de Ludwig (2012) o conhecimento científico é um produto da investigação, da prática do pensar e do observar, do agir e do tentar (repetir experimentos). Posteriormente deve-se ter planejamento, onde o pesquisador traça caminhos de acordo com as condições a serem desenvolvidas.

Pesquisa é a aplicação de um conjunto de métodos planejados e testados. Para receber o cunho de Pesquisa Científica é preciso se desenvolver de forma organizada, sistemática, seguido de um planejamento, e assim determinar o projeto do estudo, bem como técnicas voltadas a fim de alcançar o objetivo. É uma atividade racional que busca explicações para uma realidade (fatos/fenômenos), mas que nem sempre se apresentam da forma como o pesquisador “quer” explicar ou “quer” compreender (FARIAS FILHO, 2015).

"Novas áreas científicas trazem com elas novas oportunidades de crescimento e conexões com outros campos já estabelecidos", conforme cita Radosevic (apud PIERRO, 2014). A função de um pesquisador no contexto científico é, além de aprimorar os seus conhecimentos, contribuir com novos achados adequados à realidade estudada e verificar quais poderão ser desenvolvidos e aplicados.

Farias Filho (2015) cita que é de fundamental importância e empenho do pesquisador iniciante pois fará toda a diferença na busca e reflexão de fatos novos, assim um estudo terá uma perspectiva inovadora. 
A partir de eventos que tratem nas diversas áreas da ciência, como iniciações científicas, surge interesses para os pesquisadores aprofundarem na sua área de conhecimento. Segundo Cruz e Lages (2018), "quando um pesquisador ingressa num projeto de ciência, logo na educação básica, o estudante é incentivado a articular o ensino com experiências práticas", contribuindo assim, para o aumento do desempenho do estudante, incremento em sua vida acadêmica e ainda com o avanço de novas descobertas que servirão para melhoria da qualidade de vida material e intelectual da humanidade.

\section{Desafios da Pesquisa Científica}

Os dados coletados relacionados ao total de pesquisadores dispararam de $77.649 \mathrm{em}$ 2004 para 180.262 em 2016 (CNPQ apud SANCHES, 2016). Esse aspecto é positivo e corrobora com a premissa de que um país não faz ciência se não houver investimento financeiro em cientistas e laboratórios, visto que o progresso está naquilo de positivo que a ciência pode oferecer a um país e aos seus cidadãos. Porém, esses investimentos são necessários, mas não são suficientes. Observa-se que a situação do apoio à pesquisa científica no Brasil "ainda sofre, muito mais do que de falta de recursos, de uma burocracia sem fim que atravanca toda e qualquer iniciativa". Além disso, os cientistas brasileiros enfrentaram "grandes desafios em 2016, com cortes ainda maiores nos orçamentos e a arrecadação menor afetando as agências de financiamento" (SANCHES, 2016, s/p).

Ainda que sejam disponibilizados recursos para organizações sociais parceiras, onde esses devem ser utilizados para a manutenção de programas executados em parceria com o MEC, esses recursos servirão para fortalecer as atividades de educação complementares e todo o sistema educacional e de pesquisa brasileiro, conforme destaca afirma Sigollo (apud BRASIL, 2018). Esses incentivos permitem que as atividades da educação Brasileira venham a se desenvolver com mais rigor, já que o investimento é necessário.

Gonzaga (2011) enfatiza que as pesquisas visam à melhoria e à evolução material e intelectual da sociedade, e permitem que sejam criadas novas políticas públicas direcionadas ao bem-estar social. Torna-se importante por produzir conhecimentos, responder a hipóteses e a problemas que precisam ser desbravados, conforme destaca Pontes (2017), dados os novos cenários que surgem a cada dia.

Dentre os principais desafios para a pesquisa científica estão, maior investimento em pesquisa e desenvolvimento (P\&D), no número de pesquisadores ativos, na qualidade da 
produção e na internacionalização da ciência brasileira. Isso faz com que a formação de pesquisadores críticos afim de pôr em práticas pesquisas que servirão como qualitativo para a sociedade venha se desestimular. Outros aspectos que se destacam são a falta de informações, fazendo com que existam más práticas nas execuções das atividades de pesquisa e também a falta de exploração em pesquisas institucionais, onde apresentar-se-iam termos técnicos e habilidades, para assim tornar os estudos, de fato, documentos colaborativos (QUEIROZ, 2015).

Melo (2018), relata que para que haja sucesso educacional, tornando pesquisadores com aprofundamento científico, precisa-se transformar a sala de aula em algo que se possa viver; a fim de pôr em prática os acontecimentos diários e relacioná-los ao exercício da ciência.

\section{Pesquisas em Administração}

Sanches $(2016, \mathrm{~s} / \mathrm{p})$ cita que "a pesquisa científica brasileira corresponde a apenas 3\% da pesquisa científica mundial" e que o Brasil ocupa a 24 posição na publicação de artigos, segundo ranking da Nature index, onde estas, advém de áreas como física, ciências da vida, ciências ambientais e química. A autora ainda destaca: “as empresas brasileiras ainda não exploram o potencial da interação com institutos de pesquisa e universidades" (SANCHES, 2016), porém ressalta que muitos pesquisadores consideram o país com um enorme potencial para pesquisa e que esta já está em nível elevado dado o aprimoramento do parque tecnológico e formação de mestres e doutores.

Roesch (2013) menciona a importância da aprendizagem de técnicas e métodos de pesquisa, bem como aprofundar o desenvolvimento do pensar cientificamente tendo assim iniciativas criativas, minimizando assim os problemas das pesquisas, dentre eles associado a plágio, visto que pesquisa realizada em 2018 pela Unicamp aponta que 87\% dos estudantes relatam o desconhecimento sobre características do plágio, o estudo foi coletado ingressantes veteranos, visto um alto nível do não conhecimento de um assunto de grande importância no ciclo acadêmico (PACÍFICO,2018).

As universidades precisam aprofundar o seu conhecimento quando diz respeito ao incentivo em busca das pesquisas, desde o seu planejamento até a sua aplicação. $\mathrm{Na}$ universidade o conhecimento deve ser construído pela experiência ativa do acadêmico, o professor precisa da prática da pesquisa para ensinar com qualidade, já o aluno precisa dela para aprender de forma eficaz (SEVERINO, 2016). 
Segundo a Portal Educação (2017) contemporaneamente, os pesquisadores em administração, tem feito significativos progressos na área científica. É possível constatar que novas técnicas estão sendo desenvolvidas e rigorosos procedimentos de pesquisa estão avançando rapidamente. Softwares e métodos "poderosos" têm contribuído para este movimento. Gomes e Araújo (2009 apud PORTAL EDUCAÇÃO, 2017) descrevem que a pesquisa científica na área da administração ainda é alvo de grandes discussões, visto que ela não possui um método de investigação próprio.

\section{Método}

O estudo em questão trata-se de uma pesquisa qualitativa básica (MERRIAN, 1998 apud TEIXEIRA, 2003), com objetivo descritivo (MARKONI E LAKATOS, 2017) a partir de um estudo multicasos (YIN, 2001). Sua estruturação se deu inicialmente a partir do levantamento dos trabalhos de conclusão de curso realizados no curso de administração para posterior seleção daqueles que se adequaram ao perfil preestabelecido.

Dentre os 52 trabalhos levantados, determinou-se como critérios para inclusão e análise nesse estudo aqueles que se enquadrassem como estudos de caso, realizados na cidade de Juazeiro do Norte-Ce, e que em seus resultados apresentassem sugestões para melhorias. Chegou-se desse modo ao quantitativo de quatro empresas, conforme quadro abaixo.

Quadro 1: Descrição dos Trabalhos de conclusão de curso selecionados

\begin{tabular}{|l|l|}
\hline Empresa & \multicolumn{1}{c|}{ Título do Trabalho de Conclusão de Curso } \\
\hline Emp. A & Indicadores de desempenho logístico, sob a perspectiva do balanced scorecard \\
\hline Emp. B & Qualidade em serviço de saúde em clínicas médicos: um estudo de caso múltiplos \\
\hline Emp. C & Qualidade em serviço de saúde em clínicas médicos: um estudo de caso múltiplos \\
\hline Emp. D & Proposta para minimização de desperdícios no setor de corte em uma empresa de uniformes \\
\hline
\end{tabular}

Fonte: Dados da Pesquisa (2018).

Como critérios de exclusão, foram eliminados os trabalhos que, embora fossem estudos de caso, não foram realizados na cidade de Juazeiro do Norte-CE, bem como os trabalhos que apresentaram mais de uma organização para pesquisa.

O método de coleta de dados deu-se por meio entrevistas e observação dos processos apontados nos estudos. Para a análise dos dados obtidos, foram realizadas leituras do conteúdo e uma codificação flutuante, que consiste em estabelecer relação com os dados a se analisar. Os 
relatos dos entrevistados foram analisados através da Análise de Conteúdo (AC). Essa forma de analisar visa organizar os relatos dos indivíduos em categorias temáticas, quanto ao que os mesmos falam em comum sobre o assunto abordado, e para isso elaborando explicações a partir destes. Bem como, essa análise permite comparar as falas com a literatura existente de modo a enriquecê-la com novos dados e informações (MINAYO, 2010).

A análise de conteúdo é referida por Minayo (2010), como sendo uma exposição de resultados qualitativos, partindo dos depoimentos, sob a forma de discursos sínteses. Expressa, ainda, o pensamento de um agrupamento, tendo em vista que essa coletividade torna-se o emissor do discurso. A pesquisa respeitou os preceitos éticos da resolução 510/16, que discorre sobre a não maleficência aos participantes da pesquisa, visto que estes tiveram seus direitos resguardados, onde foi esclarecido acerca do estudo e os entrevistados assinaram o Termo de Consentimento Livre e Esclarecido e Pós esclarecido para que fiquem cientes da importância para participação na pesquisa, bem como dos seus direitos relativos ao estudo.

\section{Análise e Discussão dos Resultados}

Dado o levantamento feito nos trabalhos concluídos em 2017, foi possível chegar aos resultados propostos a 04 empresas, aqui denominadas pelos administradores (ADM 01 até ADM 04). Foram determinadas as seguintes categorias a serem analisadas: conhecimentos, aplicações, incremento ou modificações, avaliações e benefícios.

QUADRO 1: Conhecimento sobre os Resultados da Pesquisa

\begin{tabular}{|l|l|l|l|}
\hline Sujeitos & Resposta & Recorte & Categoria \\
\hline ADM-1 & $\begin{array}{l}\text { Toda a pesquisa eu tomei total conhecimento, pois } \\
\text { o pesquisador era estagiário da empresa, então } \\
\text { toda pesquisa foi feita através do meu } \\
\text { conhecimento. }\end{array}$ & $\begin{array}{l}\text { (...)toda pesquisa foi } \\
\text { feita através do meu } \\
\text { conhecimento }\end{array}$ & Conhecimento \\
\hline ADM-2 & $\begin{array}{l}\text { Sim, foi feito um levantamento com os nossos } \\
\text { clientes para saber o nível de satisfação, e todos os } \\
\text { dados da pesquisa tive total conhecimento. }\end{array}$ & $\begin{array}{l}\text { (...) todos os dados da } \\
\text { pesquisa tive total } \\
\text { conhecimento }\end{array}$ & Conhecimento \\
\hline ADM-3 & $\begin{array}{l}\text { A pessoa que fez a pesquisa após ter feito nos } \\
\text { comunicou que foram ótimos em relação ao nível } \\
\text { de satisfação dos clientes, disse que não teve } \\
\text { nenhum ponto negativo, então tivemos o } \\
\text { conhecimento do que estava sendo feito e também } \\
\text { do que foi apresentado por sua pesquisa. }\end{array}$ & $\begin{array}{l}\text { (...)tivemos o } \\
\text { conhecimento do que } \\
\text { estava sendo feito e } \\
\text { também do que foi } \\
\text { apresentado por sua } \\
\text { pesquisa. }\end{array}$ & Conhecimento \\
\hline ADM-4 & $\begin{array}{l}\text { Através de um trabalho que já estava acontecendo } \\
\text { na empresa, a pesquisa do aluno veio para agregar } \\
\text { valor, tomando assim todo o meu conhecimento } \\
\text { em relação aos processos na qual estavam sendo } \\
\text { feito. }\end{array}$ & $\begin{array}{l}\text { veio para agregar valor, } \\
\text { tomando assim todo o } \\
\text { meu conhecimento. }\end{array}$ & Conhecimento \\
\hline
\end{tabular}

Fonte: Dados da pesquisa (2018) 
Foram quatro participantes, que que consentiram a realização da pesquisa, envolvidos nas etapas de realização, comprovando assim a percepção de Ramos (2009).

Este aspecto valida o estudo no tocante à responsabilidade e o compromisso com o qual se aplicam métodos para levantamento de dados e possível modificação do ambiente de pesquisa após os achados. Os relatos também deixam claros o papel do pesquisador a partir do que foi descrito pelo entrevistado 2, onde cita que "foi feito levantamento", colaborando o que foi mencionado por Ludwig (2012).

Esses dados são significativos na decisão da realização de incrementos a serem aplicados no ambiente estudado, pois a pesquisa básica contribui para a geração de conhecimento, mas esta precisa ser testada, experimentada ou aplicada a uma realidade ex post facto.

QUADRO 2: Aplicação e Incremento da pesquisa

\begin{tabular}{|c|c|c|c|}
\hline Sujeitos & Resposta & Recorte & Categoria \\
\hline ADM-1 & $\begin{array}{l}\text { Houve o incremento da ferramenta na qual foi o } \\
\text { BSC, no setor no qual a estagiária que também } \\
\text { era a pesquisadora prestava serviço, já utilizamos } \\
\text { em outros setores a ferramenta, mais nesse setor } \\
\text { foi aplicado a partir da pesquisa. Aplicamos a } \\
\text { ferramenta BSC no setor de conferência, } \\
\text { inclusive ainda utilizamos das ferramentas nesse } \\
\text { setor e em vários outros setores da empresa. }\end{array}$ & $\begin{array}{l}\text { Incremento da } \\
\text { ferramenta (...) no setor } \\
\text { de conferência }\end{array}$ & $\begin{array}{l}\text { Aplicação e } \\
\text { Incremento }\end{array}$ \\
\hline ADM-2 & $\begin{array}{l}\text { Foi feito modificações nos atendimentos, a gente } \\
\text { tentou o máximo passar para o nosso cliente o } \\
\text { maior nível de qualidade em relação a tudo, } \\
\text { atendimento principalmente. Prestando assim um } \\
\text { serviço de qualidade. Agente aplicou sim, } \\
\text { colocamos uma caixinha na qual está disponível } \\
\text { para o cliente a avaliação do nosso serviço, e a } \\
\text { gente faz avaliação para tentar detectar se há } \\
\text { alguma falha e tenta mudar }\end{array}$ & $\begin{array}{l}\text { Modificações nos } \\
\text { atendimentos } \\
\text { (..)Prestando assim um } \\
\text { serviço de qualidade. }\end{array}$ & $\begin{array}{l}\text { Aplicação e } \\
\text { Modificação }\end{array}$ \\
\hline ADM-3 & $\begin{array}{l}\text { Após a pesquisa incrementamos uma caixinha } \\
\text { que serve para pesquisa e sugestões dos clientes. } \\
\text { Foi aplicado a coleta de informações dos clientes, } \\
\text { que é a caixa do nível de satisfação. }\end{array}$ & $\begin{array}{l}\text { Incrementamos uma } \\
\text { caixinha (...) pesquisa e } \\
\text { sugestões dos clientes. }\end{array}$ & Incremento \\
\hline ADM-4 & $\begin{array}{l}\text { Dentro de um pacote de mudanças que já vinham } \\
\text { ocorrendo dentro da empresa, a aplicação da } \\
\text { pesquisa foi feito no setor de cortes, na qual foi a } \\
\text { ferramenta POP, que inclusive veio a ser } \\
\text { implantada depois em outros setores da empresa, } \\
\text { foi através dessa pesquisa que conseguimos } \\
\text { detectar o gargalo da empresa, que no entanto era } \\
\text { o setor de corte no qual foi o primeiro setor a ser } \\
\text { implantado o POP. Aplicamos todas as sugestões } \\
\text { propostas na qual gerarão grandes valores, além } \\
\text { da ferramenta POP (PROCEDIMENTO } \\
\text { OPERACIONAL PADRÃO) }\end{array}$ & $\begin{array}{l}\text { Aplicação da pesquisa } \\
\text { foi feito no setor de } \\
\text { cortes, na qual foi a } \\
\text { ferramenta POP. }\end{array}$ & $\begin{array}{l}\text { Incremento } \\
\text { (Aplicação) }\end{array}$ \\
\hline
\end{tabular}

Fonte: Dados da pesquisa (2018) 
Visto que o objetivo da questão foi identificar de que forma a pesquisa se apresentou dentro das organizações, já que o seu papel é de estudar o ambiente, trazendo "modificação" ou "incremento, comprova-se a necessidade de modificação, a partir de uma série de estudo e análise (FARIAS, 2015). Os dados mostram que as pesquisas realizadas trouxeram um diagnóstico, onde se apresentava suas necessidades e estas foram acatadas e implementadas pelos gestores.

Percebe-se que o sentido que leva a estudar novos horizontes, assim citado por Rodosevic (2014), traz benefícios para o ambiente estabelecido, como a identificação de um problema que foi solucionado e comprovado a partir da pesquisa, como relata o pesquisado 4 "através dessa pesquisa que conseguimos identificar o gargalo da empresa".

A pesquisa é responsável pela construção de conhecimento, através dela encontram-se respostas para as questões que surgem no dia-a-dia. Uma produção científica para ser útil é necessária que tenha qualidade e que os resultados obtidos sejam disponibilizados para a sociedade interessada, é preciso expor, para fazer suas aplicações necessárias. Propor um plano e assim solucionar problemas, analisando as novas práticas que ali foram adotadas, como apresentado na percepção de Becker (2013).

QUADRO 3: Importância do Feedback

\begin{tabular}{|c|c|c|c|}
\hline Sujeitos & Resposta & Recorte & Categoria \\
\hline ADM-1 & $\begin{array}{l}\text { Foi importante para sabermos o que foi levantado } \\
\text { através da ferramenta e assim, no final fizemos } \\
\text { uma avaliação e tomamos conta de todo o parecer } \\
\text { do balanço. }\end{array}$ & $\begin{array}{l}\text { Avaliação final do } \\
\text { balanço }\end{array}$ & Avaliação \\
\hline ADM-2 & $\begin{array}{l}\text { No feedback tivemos um alto nível de pontos } \\
\text { positivos, mais tivemos pontos negativos, no qual } \\
\text { fizemos com que melhorasse. }\end{array}$ & $\begin{array}{l}\text { No feedback tivemos um } \\
\text { alto nível de pontos } \\
\text { positivos. }\end{array}$ & Feedback \\
\hline ADM-3 & $\begin{array}{l}\text { Ela mim passou sim o feedback, disse que os } \\
\text { clientes teve o alto nível de satisfação. }\end{array}$ & $\begin{array}{l}\text { nível de satisfação dos } \\
\text { clientes }\end{array}$ & Parecer \\
\hline ADM-4 & $\begin{array}{l}\text { Muito importante, assim todos os gestores da } \\
\text { empresa ficaram cientes das novas ferramentas que } \\
\text { estavam sendo inseridas na empresa, podendo } \\
\text { assim irem se adaptando aos procedimentos } \\
\text { operacionais padrão, tomando a organização por si } \\
\text { mesmo e fazendo com que os crescimentos de } \\
\text { qualidade da empresa se tornasse contínuo. }\end{array}$ & $\begin{array}{l}\text { Muito importante, assim } \\
\text { todos os gestores da } \\
\text { empresa ficaram cientes } \\
\text { das novas ferramentas } \\
\text { que estavam sendo } \\
\text { inseridas na empresa }\end{array}$ & Parecer \\
\hline
\end{tabular}

Fonte: Dados da pesquisa (2018)

Nessa seção analisou-se que todos os participantes mencionaram sobre a importância de receber o "parecer", que, no entanto, pode ser considerado como feedback, nas falas dos entrevistados 3 e 4 , é mencionado o que é mostrado pelo feedback podendo assim o gestor ficar “ciente" (entrevistado 04) e a saber o "nível de satisfação" (entrevistado 03) e poder 
desenvolver critérios de melhoria, seja em novas políticas ou até mesmo para identificação de fatores negativos, como mencionado pela entrevista 2 “ (...) tivemos pontos negativos, no qual fizemos com que melhorasse". No entanto, só permite uma melhoria se for discutido o que foi estudado para assim dar o direcionamento correto (GONZAGA, 2011).

O intuito seguinte foi de descobrir o ponto chave da pesquisa, e qual foi a finalidade dos estudos de caso, como assim divulgado nas pesquisas as quais foram estudadas para propagar este novo estudo, que, no entanto, foram divulgados nos resultados das pesquisas primárias.

No tocante aos benefícios da pesquisa no âmbito profissional, foram mencionadas as "aplicações" (citado 4 vezes), como aplicação de ferramentas, diagnósticos para avaliar nível de satisfação dos clientes. Visto que além das aplicações, houve algumas modificações a partir do que foi proposto, a adequação é fundamental, a pesquisa é capaz de mensurar e detectar o que é necessário para aplicação, quando é feito a última etapa já mencionada, a adequação deve ser conforme a necessidade da organização pesquisada.

QUADRO 4: Modificação do que foi proposto

\begin{tabular}{|l|l|l|l|}
\hline Sujeitos & Resposta & Recorte & Categoria \\
\hline ADM-1 & $\begin{array}{l}\text { Através dos acompanhamentos da pesquisa, foi } \\
\text { feito as devidas mudanças que eram necessárias e } \\
\text { que a ferramenta nós mostramos como algo } \\
\text { negativo, por isso a necessidade mudar. No entanto } \\
\text { a melhoria é constante para a empresa adequando } \\
\text { as necessidades. }\end{array}$ & $\begin{array}{l}\text { Através dos } \\
\text { acompanhamentos da } \\
\text { pesquisa (...) } \\
\text { adequando as } \\
\text { necessidades. }\end{array}$ & $\begin{array}{l}\text { Acompanhamento } \\
\text { (Modificações } \\
\text { Propostas) }\end{array}$ \\
\hline ADM-2 & $\begin{array}{l}\text { Não, o que foi proposto continuaremos colocando } \\
\text { em prática, pois é com esse tipo de avaliação que } \\
\text { conseguimos detectar as falhas. }\end{array}$ & $\begin{array}{l}\text { o que foi proposto } \\
\text { continuaremos } \\
\text { colocando em prática }\end{array}$ & $\begin{array}{l}\text { Avaliação } \\
\text { (Modificações } \\
\text { Propostas) }\end{array}$ \\
\hline ADM-3 & $\begin{array}{l}\text { O que foi nos passado através do feedback serviu } \\
\text { para nos nortear como saber a opinião dos clientes } \\
\text { então não modificaria em nada que foi proposto. }\end{array}$ & $\begin{array}{l}\text { modificaria em nada } \\
\text { que foi proposto. }\end{array}$ & $\begin{array}{l}\text { Modificações } \\
\text { Propostas }\end{array}$ \\
\hline ADM-4 & $\begin{array}{l}\text { Modificamos conforme foi havendo necessidade, } \\
\text { no primeiro momento utilizamos da ferramenta } \\
\text { visto que tudo estava correndo bem, hoje a gente } \\
\text { adequa conforme vamos detectando que está } \\
\text { surgindo algum erro }\end{array}$ & $\begin{array}{l}\text { Modificamos } \\
\text { conforme foi havendo } \\
\text { necessidade }\end{array}$ & $\begin{array}{l}\text { Modificações } \\
\text { Propostas }\end{array}$ \\
\hline
\end{tabular}

Fonte: Dados da pesquisa (2018)

Assim cita Pontes (2017), a cada dia surgem novos horizontes de pesquisa, no entanto a modificação nos ambientes organizacionais são de total importância e devem ser feitas conforme as necessidades. Dois entrevistados informaram sobre a necessidade de adequação das suas ferramentas após apontado o resultado, visto isso nas falas do entrevistado 01 "a 
ferramenta nos mostrou como algum ponto negativo, por isso a necessidade mudar" e do entrevistado 04 "Modificamos conforme foi havendo necessidade".

Cabe destacar, o que a pesquisa instiga durante os seus processos, desde as dificuldades enquanto pesquisado e também no que diz respeito aos incentivos, sejam eles acadêmicos ou governamentais (QUEIROZ, 2015 e SEVERINO, 2016).

QUADRO 5: O papel da pesquisa dentro da empresa e os seus benefícios

\begin{tabular}{|c|c|c|c|}
\hline Sujeitos & Resposta & Recorte & $\begin{array}{l}\text { Categori } \\
\text { a }\end{array}$ \\
\hline ADM-1 & $\begin{array}{l}\text { É muito importante pois ela apresenta a parte } \\
\text { empírica para dentro da prática, fazendo com que } \\
\text { nós gestores venha a olhar de outra maneira, pois } \\
\text { a pesquisa tem o papel de aprofundar cada } \\
\text { detalhe e nos mostra aquilo que nos dentro da } \\
\text { empresa não conseguimos enxergar. }\end{array}$ & $\begin{array}{l}\text { É muito importante pois } \\
\text { ela apresenta a parte } \\
\text { empírica para dentro da } \\
\text { prática (..)o papel de } \\
\text { aprofundar cada detalhe }\end{array}$ & Benefícios \\
\hline ADM-2 & $\begin{array}{l}\text { É importante porque a partir da pesquisa é que } \\
\text { vamos ver o que a empresa precisa melhorar, o } \\
\text { que está a bom a gente melhora, e o que este } \\
\text { negativo a gente faz com que mude. Traz com } \\
\text { certeza benefício, tem um benefício de trazer } \\
\text { qualidade aos serviços. }\end{array}$ & $\begin{array}{l}\text { a partir da pesquisa é } \\
\text { que vamos ver o que a } \\
\text { empresa precisa } \\
\text { melhorar (...) tem um } \\
\text { benefício de trazer } \\
\text { qualidade aos serviços. }\end{array}$ & Benefícios \\
\hline ADM-3 & $\begin{array}{l}\text { A pesquisa vem para agregar e somar, faz com } \\
\text { que no piscar de olhos você consiga uma } \\
\text { proposta de melhoria, que vai agregar um valor } \\
\text { significativo para empresa, que muitas vezes o } \\
\text { gestor não conseguiu ver as falhas e a pesquisa } \\
\text { vem pra fazer esse papel de melhoria continua, } \\
\text { sem os dados da pesquisa não pode ter mudanças. }\end{array}$ & $\begin{array}{l}\text {.A pesquisa vem para } \\
\text { agregar e somar, } \\
\text { (...)papel de melhoria } \\
\text { contínua }\end{array}$ & Benefícios \\
\hline ADM-4 & $\begin{array}{l}\text { É essencial esta relação do pesquisador com o } \\
\text { mercado, para que haja o desenvolvimento de } \\
\text { ambos. A academia é um momento de estudo no } \\
\text { qual fomenta o conhecimento, mais que se não } \\
\text { tiver próximo as empresas ela perde o seu valor } \\
\text { de gerar profissionais para o mercado. Traz } \\
\text { consigo vários benefício, como agregação de } \\
\text { conhecimento, de valores, aplicação de novas } \\
\text { práticas que dão o sentido inovador. }\end{array}$ & $\begin{array}{l}\text { A academia é um } \\
\text { momento de estudo no } \\
\text { qual fomenta o } \\
\text { conhecimento, (...)Traz } \\
\text { consigo vários benefício } \\
\text { (..) o sentido inovador. }\end{array}$ & Benefícios \\
\hline
\end{tabular}

Fonte: Dados da pesquisa (2018)

No atinente aos benefícios da pesquisa no âmbito profissional, ficou destacado que foram "vários benefícios" (citado 2 vezes) adquiridos com a pesquisa, e são aplicados no ambiente profissional e propulsionando um ambiente inovador (FARIAS, 2015).

Os participantes apontaram duas vezes "Melhoria", onde todo os benefícios trazidos pela pesquisa têm o papel de uma melhoria contínua. Assim como a percepção do portal educação (2017), onde os pesquisadores em administração tem feito significativos progressos na área científica. É possível constatar que novas técnicas estão sendo desenvolvidas e rigorosos procedimentos de pesquisa estão avançando rapidamente. É visto claramente na fala 02 “A 
pesquisa vem para agregar e somar, faz com que no piscar de olhos você consiga uma proposta de melhoria, que vai agregar um valor significativo para empresa”.

\section{Considerações Finais}

A pesquisa científica diz respeito à capacidade de produzir conhecimento adequado à compreensão de determinada realidade. Todo resultado de um processo investigado, o principal objetivo é resolver problemas e esclarecer dúvidas, utilizando vários procedimentos científicos. A investigação se caracteriza como a composição do ato de estudar, observar, analisar e experimentar os fenômenos, deixando de lado uma concepção estruturada a partir de visões superficiais, imediatas e subjetivas.

A pesquisa, além de ser uma via para a construção de conhecimento e informações, é base para o progresso humano no mundo científico, tecnológico e cultural. Nesse contexto, as universidades tendem a deixar a desejar em questão de ensino, fazendo com que os discentes venham a se desmotivar para construção da mesma e deixando de expor suas ideias principalmente no meio organizacional.

Inicialmente foram-se avaliados e classificados os trabalhos de interesse para o estudo em questão. Posteriormente foi analisado o que os entrevistados afirmam observando que a pesquisa científica contribui de maneira significativa para o meio organizacional, isso relacionado a partir de pesquisas realizadas durante a graduação e os benefícios de suas aplicações. Mostrando também a importância do papel de um pesquisador para detectar as falhas de uma organização e os incrementos necessários.

Visto que o objetivo inicial da pesquisa foi alcançado, que foi verificar a incidência de aplicação dos resultados coletados a partir dos estudos de caso realizados no ano de 2017. Além disso, foi perceptível, o valor que a realização da pesquisa tem durante a graduação, que contribui de maneira significativa, tanto na academia, quanto no meio organizacional.

Portanto, a realização desse estudo forneceu de forma positivo para o pesquisador, podendo ampliar a visão a respeito da pesquisa científica, assim mostrando para os novos pesquisadores a importância de novos trabalhos e os benefícios que acarretam, principalmente na área que se refere a parte administrativa, para analisar assim os gargalos e compreender o andamento da organização já que o mercado se modifica de forma muito rápida. 


\section{Referências}

ALVES, R. Filosofia da Ciência: Introdução ao jogo e suas regras. Editora Brasiliense. 1981.

BELL, J. Projeto de Pesquisa: Guia para pesquisadores iniciantes em educação, saúde e ciências sociais [recurso eletrônico]. Porto Alegre: Artmed, 2008.

BECKER, Fernando. Educação e construção do conhecimento. 2. ed.Porto Alegre: Penso, 2012.

CASTELFRANCHI, Y. UFMG Jovem alia tecnologia à preocupação social, 2018. Disponível em: <https://ufmg.br/comunicacao/noticias/ufmg-jovem-alia-inovacaotecnologica-a-preocupacao-social> Acessado: 31 out. 2018.

CRUZ, L; LAGES, L. Caminhos da pesquisa científica,2018. Disponível em:<http://minasfazciencia.com.br/2018/10/15/caminhos-da-iniciacao-cientifica/> Acessado em: 31 out 2018.

FARIAS FILHO, M. C. Planejamento da pesquisa científica. 2. ed. - São Paulo: Atlas, 2015.

GIL, A. C. Teoria Geral da Administração: dos clássicos à pós-modernidade. São Paulo: Atlas, 2016.

GONZAGA, S. A Importância da Pesquisa científica. Revista de Ciências Jurídicas e Sociais, v.1, n.1, 2011, 39, Disponível em <http://revistas.ung.br/index.php/cienciasjuridicasesociais/article/view/911> Acessado em: 11 mar. 2018.

HELLER, R. Como Motivar Pessoas. 2. edição. São Paulo: Publifolha, 1999.

LUDWIG, A. C. W. Fundamentos e Práticas de Metodologia Científica. Ed.- Petrópolis, RJ: Vozes, 2012.

MALHEIROS, B. T. Metodologia da Pesquisa em Educação. Rio de Janeiro: LTC, 2011.

LAKATOS, Marina de Andrade.; MARCONI, Eva Maria, Lakatos. Fundamentos de metodologia científica 8. ed. São Paulo: Atlas, 2017.

LEÃO, Lívia; MAYNART, Maynart. Escolas estimulam projetos inovadores para incentivar os cientistas do amanhã, 2018. Disponível em: <https://gazetaweb.globo.com/portal/especial.php?c=63736> Acessado: 31 out. 2018.

MELO, Michelle. Escolas estimulam projetos inovadores para incentivar os cientistas do amanhã, 2018. Disponível em: 〈https://gazetaweb.globo.com/portal/especial.php?c=63736> Acessado: 31 out. 2018.

MINAYO, M. C. S. (org). Pesquisa Social: teoria, método e criatividade. 29. ed. Petrópolis, RJ: Vozes, 2010 (Coleção Temas sociais). Resenha. 
PONTES, E. O desafio da pesquisa científica, 2017. Disponível em <http://diariodonordeste. verdesmares.com.br/cadernos/opiniao/o-desafio-dapesquisacientifica- $1.1792768>$ Acessado em: 12 mar. 2018.

PORTAL EDUCAÇÃO. Conceito de pesquisa na administração. Disponível em $<$ https://www.portaleducacao.com.br/conteudo/artigos/administracao/conceitodepesquisanaadministracao/34195> Acessado em: 15 maio 2018.

QUEIROZ, A. Caminhos da Pesquisa: Desafios para a produção científica no Brasil. Jornal da UFG, Publicação da Assessoria de Comunicação da Universidade Federal de Goiás ANO IX - $\mathrm{N}^{\mathrm{o}} 71$ - Abril - 2015, Disponível em: <https://jornalufgonline.ufg.br/n/80181-caminhos-dapesquisa-desafios-paraaproducaocientifica-no-brasil> Acessado em: 13 mar. 2018.

RAMOS, A. Metodologia da Pesquisa Científica: como uma monografia pode abrir o horizonte do conhecimento. São Paulo: Atlas, 2009.

REVISTA v. 8, n. 3 (2017) Revista de Gestão e Projetos - GeP, Disponível em: <http://www.revistagep.org/ojs/index.php/gep> Acessado em 11 mar 2018

ROESCH, S. M. A. Projetos de estágio e de pesquisa em administração: guia para estágios, trabalhos de conclusão de curso, dissertações e estudos de caso. 3. ed. 5. Reimpr. São Paulo: Atlas, 2009.

ROESCH, S. M. A. Projetos de estágio e de pesquisa em administração: guia para estágios. São Paulo, 2013.

PACÍFICO, F. Unicamp: pesquisa mostra falta de conhecimento sobre plágio por $87 \%$ dos estudantes ingressantes, 2018. Disponível em: <https://g1.globo.com/sp/campinasregiao/noticia/2018/10/29/unicamp-pesquisa-mostra-falta-de-conhecimento-sobre-plagio-por87-dos-estudantes-ingressantes.ghtml> Acessado: 31 out 2018.

PIERRO, B. Ciência em evolução, 2014. Pesquisa FAPEPS. Disponível em $<$ http://revistapesquisa.fapesp.br/2014/08/21/ciencia-em-evolucao> Acessado em: 26 mar 2018.

RICHARDSON, R. J. Pesquisa Social: métodos e técnicas. 3.ed. São Paulo: Atlas, 1999.

SEVERINO, A. J. Metodologia do Trabalho Científico. $24^{\mathrm{a}}$ Ed. Ver. e atual. São Paulo: Cortez, 2016.

SANCHES, C. O desafio de fazer pesquisa científica no Brasil, 2016. Disponível em < http://www.labnetwork.com.br/especiais/o-desafio-defazerpesquisacientifica-no-brasil/> Acessado em: 09 mar. 2018.

SIGOLLO, Felipe. MEC libera R\$ 104 milhões para organizações sociais parceiras,2018. Disponivel em: <http://portal.mec.gov.br/busca-geral/222-noticias/537011943/70541-meclibera-r-104-milhoes-para-organizacoes-sociais-parceiras> Acessado em: 31 out. 2018.

TEIXEIRA, E. B. A análise de dados na pesquisa científica: importância e desafios em estudos organizacionais. 2003. Editora Unijuí. ano 1. n. 2. Disponível em: 
<https://www.revistas.unijui.edu.br/index.php/desenvolvimentoemquestao/article/view/84/41 $>$ Acessado em: 13 nov. 2018.

YIN, R. K. Estudo de Caso: Planejamento e Métodos. Trad. Daniel Grassi. 2.ed. Porto Alegre: Bookman, 2001.

\section{Como citar este artigo (Formato ABNT):}

OLIVEIRA, Bianca Alves; OLIVEIRA, Alyne Leite de. Estudos Científicos em Administração: A Influência dos dados coletados para melhoria organizacional. Id on Line Rev.Mult. Psic., 2019, vol.13, n.43, p. 197-211. ISSN: 1981-1179.

Recebido: 13/11/2018;

Aceito: 19/11/2018 